\title{
Endoscopic ultrasound-guided gallbladder drainage after distension with a high density solution (hyaluronic acid)
}

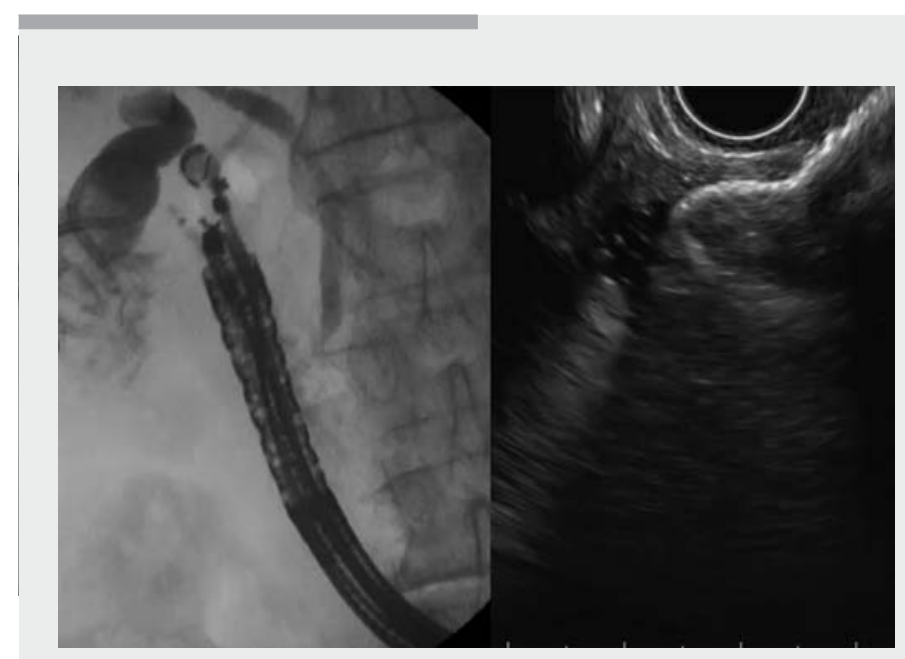

Video 1 Endoscopic ultrasound-guided gallbladder drainage with a lumen-apposing metal stent after the infusion of hyaluronic acid through a percutaneous catheter.
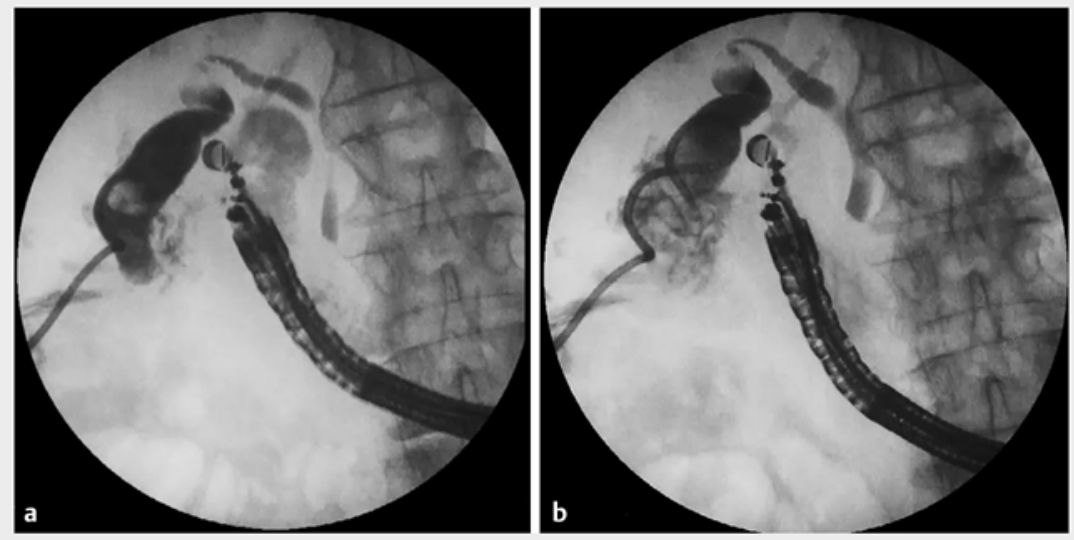

Fig. 2 Fluoroscopic images showing: a the gallbladder distended with saline and contrast instilled through the percutaneous catheter, and the passage of contrast into the duodenum via the patent cystic duct; $\mathbf{b}$ the gallbladder distended with hyaluronic acid through the percutaneous catheter.

A 95-year-old woman presented to the emergency department with clinical deterioration and vomiting. An abdominal computed tomography scan showed acute cholecystitis. She was not a candidate for surgery, therefore a percutaneous cholecystostomy was performed. In order to internalize drainage, 3 days later, the decision was made to convert the percutaneous cholecystostomy to internal transmural gallbladder drainage using a lumen-apposing metal stent (LAMS) ( $\triangleright$ Video 1 ). The gallbladder was initially difficult to visualize owing to the presence of a $3 \times 2-c m$ perivesicular abscess ( $>$ Fig. 1).

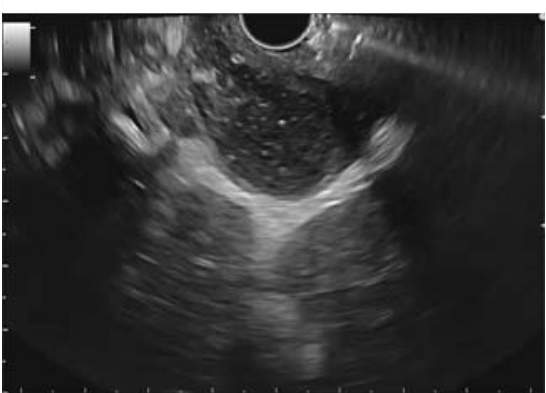

- Fig. 1 Endoscopic ultrasound image showing a $3 \times 2-\mathrm{cm}$ perivesicular abscess.

After the abscess had been completely emptied with a 19-gauge needle, a contracted gallbladder was identified. Saline and contrast were used to distend the gallbladder through the percutaneous catheter; however, the contrast quickly left the gallbladder through the cystic duct and the small perforation it contained. It was therefore not possible to distend the gallbladder enough to place a LAMS safely ( $>$ Fig. 2 a). A $2 \%$ hyaluronic acid solution was then infused through the percutaneous catheter ( $\mathbf{F i g . 2} \mathbf{b}$ ), allowing the gallbladder to distend sufficiently to place a $10 \times 10-\mathrm{mm}$ electrocautery-enhanced LAMS (Hot Axios; Boston Scientific, Marlborough, Massachusetts, USA). Finally, a 7-Fr double-pigtail stent was placed through the LAMS. The next day, the percutaneous catheter was removed. The patient improved clinically and was discharged several days later. Endoscopic ultrasound-guided gallbladder drainage (EUS-GBD) is an effective and safe technique for the treatment of acute cholecystitis in high risk patients [1]. In patients with previous percutaneous cholecystostomy, it is possible to convert the percutaneous drainage to internal transmural drainage using EUS guidance [2]. The percutaneous catheter allows the infusion of contrast to distend the gallbladder and achieve a suitable target. If, however, the cystic duct is patent, the contrast may quickly empty 
from the gallbladder, preventing adequate distension. In this scenario, the infusion of a viscous solution, in this case hyaluronic acid, can enable distension of the gallbladder by slowing the emptying through the cystic duct. EUS-guided injection of viscous solutions for gallbladder distension may be a helpful technique for EUS-guided gallbladder drainage in such challenging cases.

Endoscopy_UCTN_Code_TTT_1AS_2AG

Competing interests

Drs. Aparicio and Berzin are consultants for Boston Scientific. The remaining authors declare that they have no conflict of interest.

The authors

Lucía Medina-Prado ${ }^{1}$, Carolina MangasSanjuan¹, Belén Martínez-Moreno¹, Juan Martínez-Sempere ${ }^{1}$, Tyler M. Berzin ${ }^{2}$, José Ramón Aparicio ${ }^{1}$

1 Endoscopy Unit, Department of Gastroenterology, Hospital General
Universitario de Alicante, ISABIAL, Alicante, Spain

2 Division of Gastroenterology, Center for Advanced Endoscopy, Beth Israel Deaconess Medical Center, Harvard Medical School, Boston, Massachusetts, USA

\section{Corresponding author}

\section{José Ramón Aparicio, MD}

Unidad de Endoscopia Digestiva, Servicio de Medicina Digestiva, ISABIAL, Hospital General Universitario de Alicante, C/ Pintor Baeza 12, 03010 Alicante, Spain

japariciot@gmail.com

\section{References}

[1] Teoh AYB, Perez-Miranda M, Kunda R et al. Outcomes of an international multicenter registry on EUS-guided gallbladder drainage in patients at high risk for cholecystectomy. Endosc Int Open 2019; 7: E964-E973

[2] Minaga K, Yamashita Y, Ogura T et al. Clinical efficacy and safety of endoscopic ultrasound-guided gallbladder drainage replacement of percutaneous drainage: A multicenter retrospective study. Dig Endosc 2019; 31: 180-187
Bibliography

Endoscopy 2020; 52: E400-E401

DOI 10.1055/a-1149-1153

ISSN 0013-726X

published online 17.4.2020

(c) 2020. Thieme. All rights reserved.

Georg Thieme Verlag KG, Rüdigerstraße 14,

70469 Stuttgart, Germany

\section{ENDOSCOPY E-VIDEOS}

https://eref.thieme.de/e-videos

回政 Endoscopy E-Videos is a free Fring access online section, reporting 回: on interesting cases and new techniques in gastroenterological endoscopy. All papers include a high quality video and all contributions are freely accessible online.

This section has its own submission website at https://mc.manuscriptcentral.com/e-videos 